\title{
The Effects of Mood, Language, and Order of Songs on Writing Productivity
}

\author{
Ke Nicole $\mathrm{Hu}^{1}$ \\ ${ }^{1}$ St. Paul's School, 325 Pleasant Street, Concord, NH, United States \\ Correspondence: Ke Nicole Hu, St. Paul's School, 325 Pleasant Street, Concord, NH, United States.
}

Received: December 8, 2020

Accepted: January 14, 2021

Online Published: January 21, 2021

doi:10.5539/ijps.v13n1p12

URL: https://doi.org/10.5539/ijps.v13n1p12

\begin{abstract}
With music consumption being increasingly prominent in everyday modern life, it has become critical to examine the impact of music on the performance of cognitive tasks. Despite preexisting academic literature on the correlation between music and memorization, test-taking ability, and executive planning, conclusions from past studies regarding these cognitive tasks may not be directly applicable to writing, leaving the effects of music on writing tasks a relatively unexplored territory. Given the prevalence of music in the $21^{\text {st }}$ century among all age groups, the current study explores the effects of induced mood (happy versus sad) and language (native versus foreign) of popular songs on writing productivity, measured by number of words written in a set time period. Participants in the experiment were randomly separated into four conditions based on the language and mood of songs, and each given two argumentative writing prompts to complete while listening to the songs assigned to them. Results revealed that the induced mood of the songs significantly affected the writing productivity, with participants listening to sad music producing word counts that are significantly higher than those given happy songs. No effects, however, were found for the language of the music's lyrical content, suggesting that the language of a song has no significant impact on writing productivity.
\end{abstract}

Keywords: language, mood, motivation, music, productivity, writing

\section{Introduction}

In a world where technology has enabled unlimited access to all genres of music with a mere click of the finger, music has become increasingly prevalent in most aspects of everyday life. This quick and easy access has resulted in huge music consumption over the past decade. According to Nielsen Music's annual reports on music consumption trends, this quick and easy access has allowed daily music consumption to surge. The report revealed that Americans spend more than 4.5 hours per day listening to their favorite tunes, adding up to 32.1 hours a week (Nielsen, 2017). With streaming offerings becoming more developed and readily available than ever, Americans are often listening to music while performing other cognitive tasks. For example, students listen to music while studying, and adults have background music playing while drafting work emails. The increasing co-occurrence of music consumption and cognitive tasks raises the question of how music influences our performance and stresses the importance of understanding the effects that music has on cognition. In the current study, we examine the effects of two different aspects of music - mood and language - on writing performance.

Over the past decades, a number of research studies have helped to provide some insights into the impact of music on cognitive task performance. When examining long-term effects, growing research in the field of neuroscience has found that performing music plays a profound role in the structural development and organization of the human brain (Schlaug, 2001; Zuk, Benjamin, Kenyon, \& Gaab, 2014). In the short-term, music has also been found to impact cognitive task performance. For example, certain studies have found that students achieved higher grades while taking tests if they were listening to background music (Stanton, 1973; Cockerton, Moore, \& Norman, 1997; Cassidy \& MacDonald, 2007). However, other studies have found that listening to music is distracting and that students performed better on standardized tests when there was no background music (e.g., Fogelson, 1972). These conflicting results raise questions about the precise circumstances in which music might benefit (or harm) cognitive performance. Furthermore, while many studies have examined the effect of music on cognitive tasks including memorization, test-taking ability, and executive planning (Jäncke, 2008; Hallan, Price, \& Katsarou, 2002; Phillips, Bull, Adams, \& Fraser, 2002; Thaut, 2010), there lacks attention on the correlation between music and writing tasks. The direct psychological effects of both the specific mood of music and the language of the 
lyrics on adolescent or adult listeners remain an uncrossed territory of research, despite the prominent consumption of music while performing any task. The current study attempts to fill this research gap.

In this study, we aim to illuminate the effects of different moods and languages of music on writing productivity. The two main research questions are: 1) how does mood (happy versus sad) affect writing productivity and 2) how does the language of the text (native versus foreign) affect writing productivity. Based on empirical evidence and established theories, it was hypothesized that music in foreign languages that are associated with sad emotions would be most beneficial to writing productivity. The rationale for the proposed hypothesis lays on the basis that 1) simulating music produces more physiological arousal (emotionality), making it more distracting than sad, sedative music (which in turn, hinders writing productivity) and 2) music in the native language increases arousal and thus may hinder focus. Understanding the psychological effects of music on writing productivity can both help listeners enjoy music while making the best use of their time and help educators make more meaningful suggestions on curricular decisions.

The present study will begin with a literature review, followed by the methodology, then the results and discussions, and end with the conclusion.

\section{Literature Review}

\section{$2.1 \mathrm{Mood}$}

In the field of psychology, mood is generally defined as an emotional state that affects someone for a period of time that may last anywhere between a few seconds up to several weeks. In part, the appeal of music is its ability to influence one's mood. Previous studies revealed that different types of music have varying impacts on one's emotional state, which in turn, affects task performance (Isen, Shalker, Clark, \& Karp, 1978; Phillips, Bull et al., 2002; Zwaag, Dijksterhuis, Waard, Mulder, Westerink, \& Brookhuis, 2012). Music's ability to influence human emotion is important given the strong connections between cognitive performance and arousal of mood (Isen et al., 1978; Phillips, Bull et al., 2002; Phillips, Smith, \& Gilhooly, 2002; Oaksford, 1996). This relationship can be understood in terms of the Yerkes-Dodson law (1908), which explains that as arousal of mood increases, performance will increase up to an optimal point, beyond which it will begin to deteriorate. This law raises the question of whether certain types of music may be more likely to bring individuals' mood to the "optimal point" or whether the music may be overly stimulating so as to harm performance. To explore the application of this theory to the relationship between mood state and performance, we can examine findings from other studies.

A number of research studies indicate that different types of music can induce different mood responses (e.g., Koelsch, 2014). For example, previous studies found that upbeat, energizing music corresponds to elevated states of anxiety and physiological arousal, whereas melancholic, calm and sedative music does not (Smith \& Morris, 1976). Another study found that calming background music increases young children's performance in arithmetic and memory tasks (Hallan et al., 2002). Background music has also been shown to affect experienced mood while driving, which consequently influences driving abilities (Zwaag et al., 2012). As shown in these studies, it is evident that mood induced by music does have a significant impact on cognitive tasks, and it varies depending on the task.

Although we would expect that mood states affect writing performance, there is a lack of research studies around this topic. Previous research on music's benefits focused primarily on memorization, test-taking ability, and executive planning (Jäncke, 2008; Hallan et al., 2002; Phillips, Bull et al., 2002; Thaut, 2010). While these findings have helped us better understand the effects of music and cognition, the applications may not extend to writing. For example, there is usually no strict time-limit for writing tasks, unlike test-taking situations. Additionally, while writing does utilize one's memories, it is not strictly memory retrieval but, instead, uses logic, creativity, and other mental processes. Since many students and adults alike often listen to background music while writing, the current research examining the role of mood state elicited by music on writing productivity would give us a clearer understanding of the impact of music on this commonplace work task.

\subsection{Language in Music: Native Versus Foreign Language Lyrics}

Because lyrics and language are highly salient to individuals as they listen to music, it seems likely that lyrical content may impact cognition. There are a variety of ways that lyrical content could differ, but the language of lyrics is fundamental.

One's native language engenders a sense of familiarity that may impact one's arousal when listening to music (Johnson, Bruggeman, \& Cutler, 2018). For example, one study found that that individuals' heart rate increased significantly when listening to familiar music (Fontaine \& Schwalm, 1979). Since music in one's native language 
likely sounds more familiar than music in a foreign language, these differences in language could evoke different levels of arousal.

Additionally, some evidence indicates that music with comprehensible words tends to be more distracting than instrumental music. For example, Salame and Baddeley's (1989) study found that students who listened to vocal background music showed lower memory performance than those who were exposed to instrumental music. It is possible that foreign language songs are similar to instrumental music in that neither can be verbally understood by the listener. Therefore, it is hypothesized that native language songs may hinder writing productivity more than foreign language songs.

While much research regarding the benefits of music has been explored, the direct psychological effects of the specific mood and language of music on adolescent or adult listeners are still relatively unexplored. Previous research has not explicitly examined the effects of positive or negative mood states and native-language versus foreign-language of music simultaneously, nor has it explored the effect of music on writing productivity.

\section{Method}

\subsection{Participants}

Using a power analysis for the between-participant comparison, we determined that, in order to achieve $85 \%$ power with alpha 0.05 and $d=0.35$, the study must include 296 participants. To account for the possibility that a few participants may be excluded from the data, we recruited a total of 315 participants for the study.

Participants were recruited using Mechanical Turk and paid $\$ 1.20$ to complete the experiment. The age of the participants ranged between 18 to 69 years old, with a median age of 33 years old and a standard deviation of approximately 10 years. Among the 315 participants, $38 \%$ were female, $57 \%$ were male, and $5 \%$ categorized as other. All participants live in the United States, and 295 reported as being able to speak English well or very well. $21 \%$ of the participants achieved advanced studies (e.g., Masters, PhD, etc.), $59.7 \%$ were college graduates, $13.6 \%$ had some college experience, and the remaining $5.7 \%$ of participants were high school graduates.

Among all 315 participants, 103 reported that they spoke Korean fluently (i.e., the language in the "foreign language" condition), 10 were not fluent in English, and 7 had completed the study before, so they were excluded from the experiment. After the exclusion, there were a total of 195 participants. Participants were randomly assigned to one of four conditions on their birth date and month: (1) Upbeat English song followed by upbeat foreign-language song, (2) Upbeat foreign-language song followed by upbeat English song, (3) Downbeat English song followed by downbeat foreign- language song, and (4) Downbeat foreign-language song followed by downbeat English song, Participants were closely balanced across the four conditions (range $=46$ to 52).

\subsection{Design}

This is a $2 \times 2$ experiment in which we investigated the effects of mood (happy versus sad), language of the lyrics (Korean versus English), and order of the languages (Korean first versus English first) on writing productivity. After being randomly assigned to one of the four aforementioned conditions, each participant received two writing prompts. The first writing prompt stated "Does Technology Make Us More Connected or More Alone? Explain your answer." The second writing prompt stated "Which traits should parents instill in their children? Explain your answer." Each participant wrote their responses to the two prompts while listening to either upbeat or downbeat music; the between-participant variable is the mood of the song and the order of the languages of the lyrics. The within-participant variable is the language of the lyrics.

\subsection{Procedure}

In this experiment, participants were randomly assigned to one of four conditions. The random assignment was completed through a question that asked for the birth date and birth month of the participants. Those who had an even birth date and even birth month were assigned to group 1, participants who had an even birth date and odd birth month were sent to group 2, and so on until all participants were placed in one of four groups. This process ensured that there was no bias as a result of order, in case participants naturally wrote more first and less second, or vice versa.

In their assigned groups, participants wrote two short essays while listening to music. Before starting, participants were asked to listen to a calibration video and adjust the computer to a comfortable volume. After this adjustment, the participants were given the following instructions: "Start by clicking a video to make a song start playing. Then start writing your answer to the question you are shown. Continue writing until the song ends. Once the song ends please stop immediately (even in the middle of a sentence) and go on to the next page." As there were two prompts, the experiment was split into two main sessions, each with a duration of 3 minutes and 40 seconds. 
- Session 1. The participant received the first prompt, "Does Technology Make Us More Connected or More Alone? Explain your answer" and was given a song in a particular mood state. They write about the prompt for 3 minutes and 40 seconds while the music plays in the background.

- Session 2. The participant receives the second prompt, "Which traits should parents instill in their children? Explain your answer" and a song of the same mood state in another language. Once again, participants are asked to write for the 3 minutes 40 seconds, the duration of the song.

Both writing prompts can be categorized as argumentative, which demands consistent logic, and both prompts engage topics that are easily recognized by the majority of the population.

\subsection{Materials}

Four songs are used in this experiment, among which two are English and two are Korean. In each language, one song is happy, while the other song is sad. The English songs used in the study are "Brave" by Sara Bareilles (happy) and "Talking to the Moon" by Bruno Mars (sad). The Korean foreign-language songs are "My My" by Apink (happy) and "Elevator" by Jonghyun (sad). Each song has a duration of around 3 minutes 40 seconds, ensuring that for each prompt, participants got the same amount of time to write.

\subsection{Measures}

\subsubsection{Writing Productivity}

Writing productivity was measured by counting the number of words participants completed in their response.

\section{Results}

Each participant wrote two essays, which translates to two word counts per participant. These word counts appear to be highly correlated $(r=0.902, p<.001)$. Means and standard deviations for writing productivity for each condition are presented in Table 1.

A 2x2 mixed ANOVA examining the effects of language, language order, and mood showed that the main effect of language was not significant, nor did language interact with any other variables $(F \mathrm{~s}<1)$. There was a significant effect of mood, with more words written in the sad mood condition, $F(1,191)=4.463, p=0.036, \eta 2 \mathrm{p}=0.023$ (see Figure 1). Language order did not have a significant effect, $F(1,191)=0.299, p=0.585, \eta 2 p=0.002$, nor did mood and language order interact, $F(1,191)=2.379, p=0.125, \eta 2 \mathrm{p}=0.012$.

Table 1. Descriptive statistics for writing productivity across experimental conditions

\begin{tabular}{lccc}
\hline & N & $\begin{array}{c}\text { Prompt 1 Mean } \\
\text { Word Count }(S D)\end{array}$ & $\begin{array}{l}\text { Prompt 2 Mean } \\
\text { Word Count }(S D)\end{array}$ \\
\hline Happy Music - English First & 48 & $64.1(50.5)$ & $63.1(50.5)$ \\
Happy Music - Korean First & 49 & $46.6(57.2)$ & $46.4(57.2)$ \\
Sad Music - English First & 46 & $67.5(68.0)$ & $69.1(68.0)$ \\
Sad Music - Korean First & 52 & $75.2(57.2)$ & $77.7(63.1)$ \\
\hline
\end{tabular}




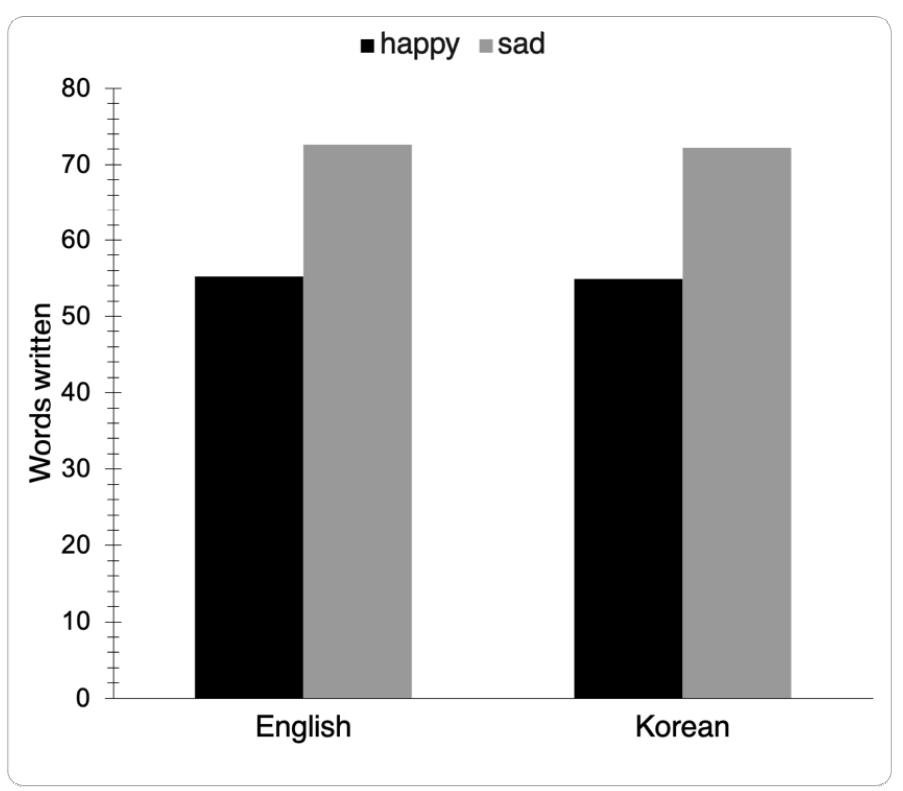

Figure 1. Words written with respect to mood and language

\section{Discussions}

The current study sheds light on several research questions related to the impact of music on writing performance. Regarding the language of the songs, the mean number of words written while listening to the English and Korean songs did not differ significantly for both the happy and the sad mood conditions, which suggests whether the song was in the native language or the foreign language did not impact writing productivity. Interestingly, when participants were asked about the songs, exactly two thirds of the listeners found the English song to be more distracting than the Korean alternative. However, as the findings showed, language had no significant impact on their writing productivity. On the one hand, participants' perceptions that language affected their performance may be illusory. On the other hand, perhaps language impacted participants' cognition in ways that were not captured by their writing productivity.

However, the mood of a song (happy or sad) appears to impact writing productivity (word count). Participants in the sad music condition showed the highest writing productivity (greatest average aggregated word count of the two prompts). Thus, sad songs appeared to be an important driver of writing productivity. One possible explanation for this finding is that sad mood states induce greater motivation. The hedonistic discounting hypothesis would suggest that sad emotion states increase future expectations of the certain task's hedonistic value and perpetuates individuals to put more effort in the completion of the task (Forgas, 2013). Another notion that could potentially explain the present study's results is the mood- repair strategy; when individuals feel down, they tend to stay more motivated and focused on their tasks as a way to distract themselves from negative memories or thoughts (Erber \& Tesser, 1992; Forgas, 2013). This motivating force induced by the sad song may have carried through to both writing tasks, encouraging the participants to write more. Lastly, previous research has found that sad, calm music is simply less distracting that energetic, upbeat music (Smith \& Morris, 1977). Therefore, rather than enhancing writing productivity, sad music may have simply compromised performance to a lesser extent than happy music. Overall, sad music seems be more beneficial to writing productivity, perhaps because it induces motivation and is less distracting.

It is important to examine how limitations of the study may have affected its results. Firstly, the data collection process was imperfect. Given that the experiment was delivered using Amazon Mechanical Turk, it was difficult to determine what was happening on the other side of the computer screen, raising questions about whether or not participants followed the instructions correctly, wrote for the entire duration of the song, or stayed focused throughout the experiment. These challenges could partly explain the large standard deviation of the word counts, as different participants may have held this experiment to varying degrees of importance. The second limitation was the sample size. Originally, a power analysis for the between-participant comparison with alpha 0.05 and $d=$ 0.35 showed that we must run 296 participants to achieve $85 \%$ power. Rounding up, the study randomly selected 315 participants using Mechanical Turk. Although we recruited more than the estimated requirement, unexpectedly, approximately $30 \%$ of the participants spoke Korean fluently and/or did not speak English fluently, which caused them to be excluded from the study, thus diminishing the actual sample size. If the sample size was 
increased, more findings may have been statistically significant. A third weakness is that the study only examined the word count, rather than analyzing other features the content of the writing (e.g., readability, sentence length, grammar). Future studies could delve deeper into the effects of music and more aspects of writing.

\section{Conclusion}

The current study examining the effects of mood and language of a song on writing productivity found that there was a statistically significant relationship between mood and writing. When sad, reflective songs were played in the background, participants were more productive with their writing compared to when they listened to happy, upbeat music. While no other findings regarding language of the song appeared to be statistically significant in the current study, it is important to note that different aspects of music may potentially have greater psychological impacts on the overall quality and productivity of writing tasks. Future research should examine whether the effect mood and order play on writing productivity may extend to other mental tasks and cognitive processes. Given the prevalence of music in today's society, the correlation between background music and writing tasks deserves further attention.

\section{References}

Blood, A. J., Zatorre, R. J., Bermudez, P., \& Evans, A. C. (1999). Emotional responses to pleasant and unpleasant music correlate with activity in paralimbic brain regions. Nature Neuroscience, 2(4), 382-387. https://doi.org/10.1038/7299

Bower, G. H. (1981). Mood and memory. American Psychologist, 36(2), 129. https://doi.org/10.1037/0003-066X.36.2.129

Brittin, R. V. (2000). Children's preference for sequenced accompaniments: The influence of style and perceived tempo. Journal of Research in Music Education, 48(3), 237-248. https://doi.org/10.2307/3345396

Brittin, R. V. (2014). Young Listeners' Music Style Preferences: Patterns Related to Cultural Identification and Language Use. Journal of Research in Music Education, 61(4), 415-430. https://doi.org/10.1177/0022429413509108

Cassidy, G., \& MacDonald, R. A. R. (2007). The effect of background music and background noise on the task performance of introverts and extraverts. Psychology of Music, 35(3), 517-537. https://doi.org/10.1177/0305735607076444

Cockerton, T., Moore, S., \& Norman, D. (1997). Cognitive Test Performance and Background Music. Perceptual and Motor Skills, 85(3_suppl), 1435-1438. https://doi.org/10.2466/pms.1997.85.3f.1435

Črnčec, R., Wilson, S. J., \& Prior, M. (2006). The cognitive and academic benefits of music to children: Facts and fiction. Educational Psychology, 26(4), 579-594. https://doi.org/10.1080/01443410500342542

Elbert, T., Pantev, C., Wienbruch, C., Rockstroh, B., \& Taub, E. (1995). Increased cortical representation of the fingers of the left hand in string players. Science, 270(5234), 305-307. https://doi.org/10.1126/science.270.5234.305

Erber, R., \& Tesser, A. (1992). Task effort and the regulation of mood: The absorption hypothesis. Journal of Experimental Social Psychology, 28(4), 339-359. https://doi.org/10.1016/0022-1031(92)90050-T

Flowers, P. (1980). Relationship Between Two Measures of Music Preference. Contributions to Music Education, (8), 47-54.

Fontaine, C. W., \& Schwalm, N. D. (1979). Effects of familiarity of music on vigilant performance. Perceptual and Motor Skills, 49(1), 71-74. https://doi.org/10.2466/pms.1979.49.1.71

Forgas, J. P. (2013). Don't Worry, Be Sad! On the Cognitive, Motivational, and Interpersonal Benefits of Negative Mood. Current Directions in Psychological Science, 22(3), 225-232. https://doi.org/10.1177/0963721412474458

Gardner, H., Silverman, J., Denes, G., Semenza, C., \& Rosenstiel, A. K. (1977). Sensitivity to musical denotation and connotation in organic patients. Cortex, 13(3), 242-256. https://doi.org/10.1016/S0010-9452(77)80034-8

Gaser, C., \& Schlaug, G. (2003). Brain structures differ between musicians and non-musicians. Journal of Neuroscience, 23(27), 9240-9245. https://doi.org/10.1523/JNEUROSCI.23-27-09240.2003

Gates, A., \& Bradshaw, J. L. (1977). The role of the cerebral hemispheres in music. Brain and Language, 4(3), 403-431. https://doi.org/10.1016/0093-934X(77)90035-9 
Greenfield, P. M., Bruzzone, L., Koyamatsu, K., Satuloff, W., Nixon, K., Brodie, M., \& Kingsdale, D. (1987). What is rock music doing to the minds of our youth? A first experimental look at the effects of rock music lyrics and music videos. The Journal of Early Adolescence, 7(3), 315-329. https://doi.org/10.1177/0272431687073007

Hallam, S., Price, J., \& Katsarou, G. (2002). The effects of background music on primary school pupils' task performance. Educational Studies, 28(2), 111-122. https://doi.org/10.1080/03055690220124551

Innes, K. E., Selfe, T. K., Khalsa, D. S., \& Kandati, S. (2016). Effects of meditation versus music listening on perceived stress, mood, sleep, and quality of life in adults with early memory loss: a pilot randomized controlled trial. Journal of Alzheimer's Disease, 52(4), 1277-1298. https://doi.org/10.3233/JAD-151106

Isen, A. M., Shalker, T. E., Clark, M., \& Karp, L. (1978). Affect, accessibility of material in memory, and behavior: A cognitive loop? Journal of Personality and Social Psychology, 36(1), 1. https://doi.org/10.1037/0022-3514.36.1.1

Johnson, E. K., Bruggeman, L., \& Cutler, A. (2018). Abstraction and the (misnamed) language familiarity effect. Cognitive Science, 42(2), 633-645. https://doi.org/10.1111/cogs.12520

Konz, S., \& Mcdougal, D. (1968). The effect of background music on the control activity of an automobile driver. Human Factors, 10(3), 233-243. https://doi.org/10.1177/001872086801000305

Kotsopoulou, A., \& Hallam, S. (2010). The perceived impact of playing music while studying: age and cultural differences. Educational Studies, 36(4), 431-440. https://doi.org/10.1080/03055690903424774

Labbé, E., Schmidt, N., Babin, J., \& Pharr, M. (2007). Coping with stress: the effectiveness of different types of

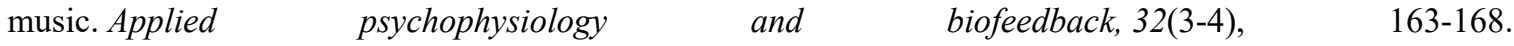
https://doi.org/10.1007/s10484-007-9043-9

Liew, T. W., \& Tan, S. M. (2016). The Effects of Positive and Negative Mood on Cognition and Motivation in Multimedia Learning Environment. Educational Technology \& Society, 19(2), 104-115.

Martin, E. A., \& Kerns, J. G. (2011). The influence of positive mood on different aspects of cognitive control. Cognition and Emotion, 25(2), 265-279. https://doi.org/10.1080/02699931.2010.491652

Oaksford, M., Morris, F., Grainger, B., \& Williams, J. M. G. (1996). Mood, reasoning, and central executive processes. Journal of Experimental Psychology: Learning, Memory, and Cognition, 22(2), 476. https://doi.org/10.1037/0278-7393.22.2.476

Peretz, I., \& Zatorre, R. J. (2005). Brain organization for music processing. Annu. Rev. Psychol., 56, 89-114. https://doi.org/10.1146/annurev.psych.56.091103.070225

Phillips, L. H., Bull, R., Adams, E., \& Fraser, L. (2002). Positive mood and executive function: Evidence from Stroop and fluency tasks. Emotion, 2(1), 12. https://doi.org/10.1037/1528-3542.2.1.12

Phillips, L. H., Smith, L., \& Gilhooly, K. J. (2002). The effects of adult aging and induced positive and negative mood on planning. Emotion, 2(3), 263. https://doi.org/10.1037/1528-3542.2.3.263

Schlaug, G. (2009). Music, musicians, and brain plasticity. Oxford Handbook of Music Psychology, 197-207. https://doi.org/10.1093/oxfordhb/9780199298457.013.0018

Smith, C. A., \& Morris, L. W. (1976). Effects of stimulative and sedative music on cognitive and emotional components of anxiety. Psychological reports, 38(3_suppl), 1187-1193. https://doi.org/10.2466/pr0.1976.38.3c.1187

Smith, C. A., \& Morris, L. W. (1977). Differential effects of stimulative and sedative music on anxiety, concentration, and performance. Psychological Reports, 41(3_suppl), 1047-1053. https://doi.org/10.2466/pr0.1977.41.3f.1047

Stanton, H. E. (1973). The effect of music on test anxiety. Australian Psychologist, 8(3), 220-228. https://doi.org/10.1080/00050067308255642

Tallal, P., \& Gaab, N. (2006). Dynamic auditory processing, musical experience and language development. Trends in Neurosciences, 29(7), 382-390. https://doi.org/10.1016/j.tins.2006.06.003

Thaut, M. H. (2010). How Music Helps to Heal the Injured Brain: Therapeutic Use Crescendos Thanks to Advances in Brain Science By Michael H. Thaut, Ph. D., \& Gerald C. McIntosh, MD. Cerebrum. 
Time with Tunes: How Technology is Driving Music Consumption. (2017, February 11). Retrieved from https://www.nielsen.com/us/en/insights/article/2017/time-with-tunes-how-technology-is-driving-music-con sumption/

Van Der Zwaag, M. D., Dijksterhuis, C., De Waard, D., Mulder, B. L., Westerink, J. H., \& Brookhuis, K. A. (2012). The influence of music on mood and performance while driving. Ergonomics, 55(1), 12-22. https://doi.org/10.1080/00140139.2011.638403

Zuk, J., Benjamin, C., Kenyon, A., \& Gaab, N. (2014). Behavioral and neural correlates of executive functioning in musicians and non-musicians. PloS one, 9(6), e99868. https://doi.org/10.1371/journal.pone.0099868

\section{Copyrights}

Copyright for this article is retained by the author(s), with first publication rights granted to the journal.

This is an open-access article distributed under the terms and conditions of the Creative Commons Attribution license (http://creativecommons.org/licenses/by/4.0/). 